\title{
Human biting rhythm of Anopheles gambiae Giles, 1902 (Diptera: Culicidae) and sleeping behaviour of pregnant women in a lagoon area in Southern Benin
}

\author{
Armel Djènontin ${ }^{1,2^{*}} \mathbb{D}$, Aziz Bouraima ${ }^{1,2}$, Christophe Soares ${ }^{1,2}$, Seun Egbinola ${ }^{3}$ and Gilles Cottrell ${ }^{4}$
}

\begin{abstract}
Objective: In the framework of EVALMOUS study aiming to assess the use and effectiveness of mosquito nets by pregnant women and other members of their household in a lagoon area in southern Benin, the behaviour of pregnant women relative to the time they go to bed using the net were recorded. Malaria vectors biting rhythm, Plasmodium falciparum infection and insecticide resistance genes in malaria vectors were also determined.

Results: Overall, 3848 females of Anopheles gambiae s. I were collected and 280 pregnant women responded to the survey. Almost all Anopheles gambiae s. I. tested were Anopheles coluzzi Coetzee and Wilkerson 2013 (Diptera: Culicidae). The CSP index in malaria vector was $1.85 \%$ and the allelic frequency of $k d r$ gene was $74.4 \%$. Around $90 \%$ of bites and Plasmodium falciparum Welch, 1897 (Haemosporida: Plasmodiidae) transmission occurred between 10 p.m. and 6 a.m., which coincides with the period when more than $80 \%$ of pregnant women were under bednet. Despite a slight early evening and early morning biting activity of malaria vectors in the study area, the good use of nets might remain a useful protection tool against mosquito biting and malaria transmission.
\end{abstract}

Keywords: Anopheles coluzzi, Biting rhythm, Malaria, Prevention, Pregnant women

\section{Introduction}

Since 2000, a significant expansion of financial support and scale-up of malaria control tools were observed [1]. Progress in terms of reduction in malaria cases and deaths followed this scale-up of malaria control tools. Despite this, malaria remains a major public health concern in Africa, with an estimated 213 million cases and $3,80,000$ deaths in 2018 [2], probably due to resistance in parasite and vectors and changes in vectors behaviour. In Benin, malaria cases increased from 10,44,235 and

\footnotetext{
*Correspondence: armeldj@yahoo.fr

${ }^{1}$ Centre de Recherche Entomologique de Cotonou (CREC), 06 BP 2604 Cotonou, Bénin

Full list of author information is available at the end of the article
}

1869 deaths to $17,68,450$ malaria cases and 2138 deaths between 2014 and 2018 .

In many malaria endemic areas including Benin, Long Lasting Insecticidal Treated Nets (LLITNs) and Indoor Residual Spraying (IRS) represent the main interventions for malaria vector control [2] as recommended by World Health Organisation (WHO). These indoor insecticidebased methods and LLITNs depend on various factors among which vectors behaviour (such as human biting rythm and endo/exophagy), human behaviour (e.g. sleeping behaviour) and insecticide resistance mechanisms in vectors. Insecticide resistance is well documented in malaria vectors in malaria endemic countries $[3,4]$. Furthermore, numerous studies across endemic countries reported behavioural changes of malaria vectors [5-7]. Early morning biting activity of Anopheles (Cellia) 
funestus Giles, 1900 (Diptera: Culicidae) following the universal coverage of LLITNs was reported in Southern Benin and authors stated that these findings might have direct consequences for malaria control in Africa [5]. Indeed, this vector could bite and transmit the parasite at times when people are not under LLITNs. EVALMOUS study assessed the use and the effectiveness of mosquito nets by pregnant women and other members of their household in preventing malaria [8]. This study was carried out in Sô-Ava district, a lagoon area with high risk for malaria vectors proliferation [9]. Entomological surveys and questionnaire were carried out to assess malaria vectors human biting activity and the sleeping behaviour of pregnant women.

\section{Main text \\ Methods \\ Study area and type of study}

EVALMOUS study was carried out in 15 villages of SôAva district $\left(6^{\circ} 28^{\prime} 00^{\prime \prime} \mathrm{N} 2^{\circ} 25^{\prime} 00^{\prime \prime}\right.$ E) located in Nokoue Lake in Southern Benin. Sô-Ava is one of the eight districts of Atlantic department with about 1,00,000 inhabitants and a surface area of $218 \mathrm{~km}^{2}$. The present study is an observational cross-sectional study nested in EVALMOUS study. Inclusion and exclusion criteria of EVALMOUS study are described in Hounkonnou et al. 2018 [8]. Any household in the EVALMOUS study that accepted overnight mosquito collection was eligible (no household refused).

\section{Mosquito collection}

Mosquito collection was carried out in 15 villages selected for EVALMOUS study, using human landing catches method (HLCs) as described by Djènontin et al., 2010 [10]. In each village, mosquito collection was carried out both indoors and outdoors of 3 human cases for 1 night (90 collection sites in all) during the rainy season between July and August 2016. Mosquitos were collected from 7 p.m. to 9 a.m. Collector teams were rotated among the collection points to minimize sampling bias.

\section{Laboratory analysis}

Mosquitoes were identified to species level using morphological criteria according to the identification keys $[11,12]$. All mosquitoes identified as Anopheles gambiae $s$. $l$. were stored in individual tubes with silica gel and preserved at $-20{ }^{\circ} \mathrm{C}$ in the laboratory.

Heads and thoraxes of anopheline females were tested by enzyme-linked immunosorbent assays (ELISA) for detection of Plasmodium falciparum circumsporozoite protein (CSP), as previously described [13].

Genomic DNA was extracted from the abdomen of all mosquito using the extraction buffer Livak [14]. The species was then identified by diagnostic Polymerase Chain Reaction (PCR) using the Scott protocol [15] and molecular characterization according to Santolamazza protocol $[16,17]$. The knockdown resistance mutation ( $k d r$-west, L1014F) was detected by Taqman allelic discrimination assays as described by Bass et al.[18].

\section{Pregnant women sleeping behaviour and bed net use}

Data regarding the time at which each pregnant woman entered and exited their house, the time each bed net user entered and exited their sleeping space the night preceding the survey were collected by questionnaire.

\section{Data analysis}

Every hour from 7 p.m. to 9 a.m, the proportion of malaria vectors collected indoors was determined, as well as the proportion of pregnant women under bed nets at each hour from 7 p.m. to 9 a.m the night preceding the survey.

The mosquito collection period was divided into 3 different timeframes (7 p.m. -10 p.m.; 10 p.m. -6 a.m.; 6 a.m. -9 a.m.). The proportion of mosquito collected at each timeframe (aggressiveness) was calculated, as well as the $95 \%$ confidence interval.

CSP index in malaria vectors Anopheles gambiae s.l. in each village was calculated as the number of positive vector divided by the total tested. Endophagy was calculated as the number of vectors collected indoors divided by the total collected. The 95\% confidence interval of the CSP index and endophagy were also estimated. Allelic frequency of $k d r$ gene mutation in Anopheles gambiae s.l. at each period was calculated. Proportions were compared using Chi-square tests.

\section{Results}

\section{Human biting rhythm and pregnant women sleeping} behaviour

Overall, 10,285 mosquitoes were caught of which 334 were Anopheles (Cellia) pharoensis Theobald, 1901 (Diptera: Culicidae) and 3848 were Anopheles gambiae s. $l$. The distribution by village of Anopheles gambiae $s . l$. is shown the Additional file 1: Table S1. A high spatial heterogeneity of abundance malaria vectors was observed (Fig. 1). The number of females of Anopheles gambiae s.l. collected ranged from 14 (corresponding to 2.33 bites per person per night in Awomey-Gbèkpa village) to 1114 (corresponding to 185.66 bites per person per night in Todo village). Respectively $1.3 \%, 90.7 \%$ and $8.0 \%$ of mosquito's aggressiveness occurred during the timeframes 7 p.m-10 p.m.; 10 p.m-6 a.m. and 6 a.m-9 a.m. (Additional file 2: Table S2). 


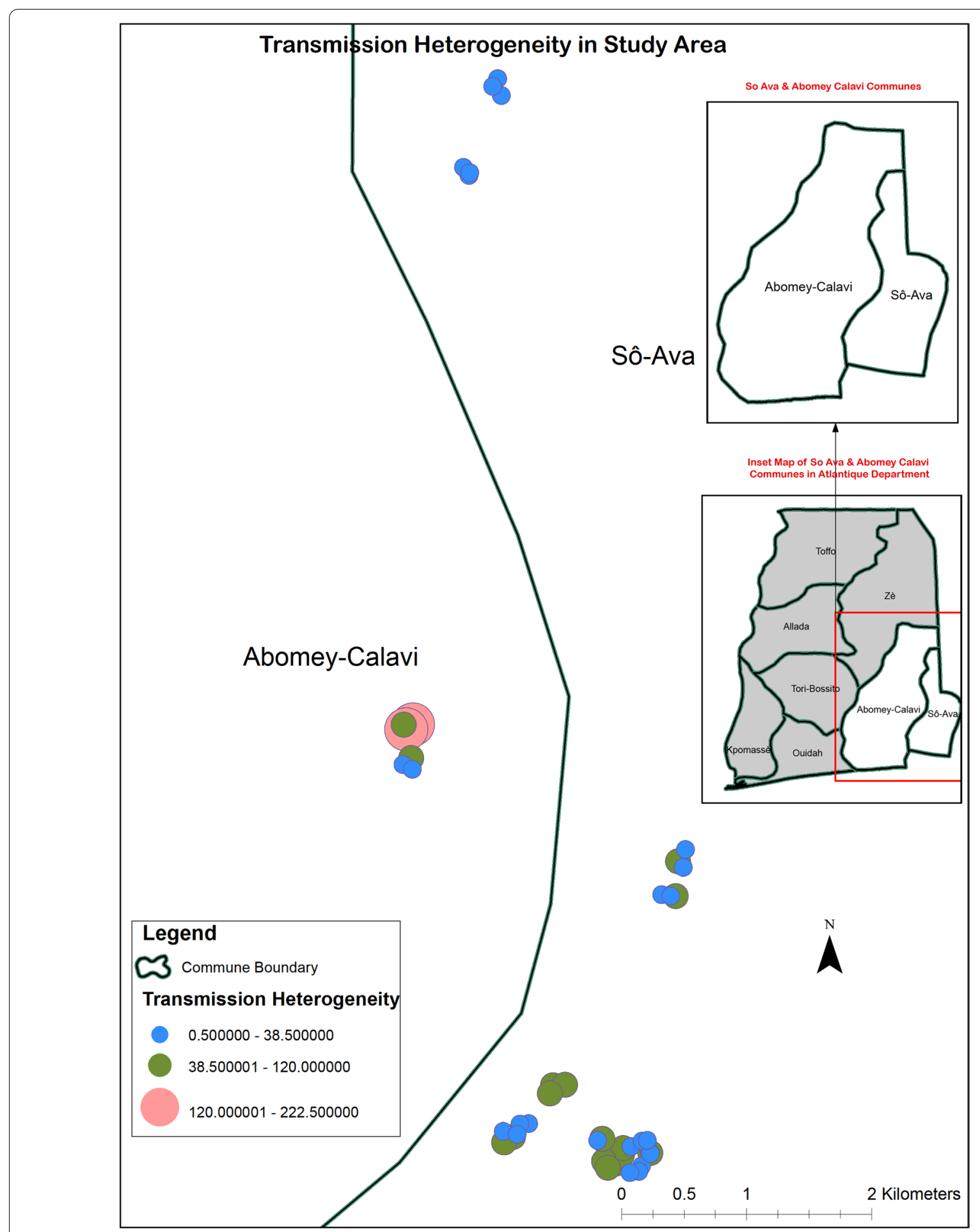

Fig. 1 Spatial heterogeneity of malaria vectors abundance in the study area

A total of 280 pregnant women responded to the survey. The proportion of pregnant women under bed net from early evening to early morning ranged from around 1\% (8 a.m-9 a.m.) to $100 \%$ (12 a.m-3 a.m.) (Fig. 2). From
10 p.m. to 6 a.m., where around $90 \%$ of aggressiveness and transmission occurred in the study area during the survey, $85.5 \%$ of pregnant women were under bed net (Fig. 2). 


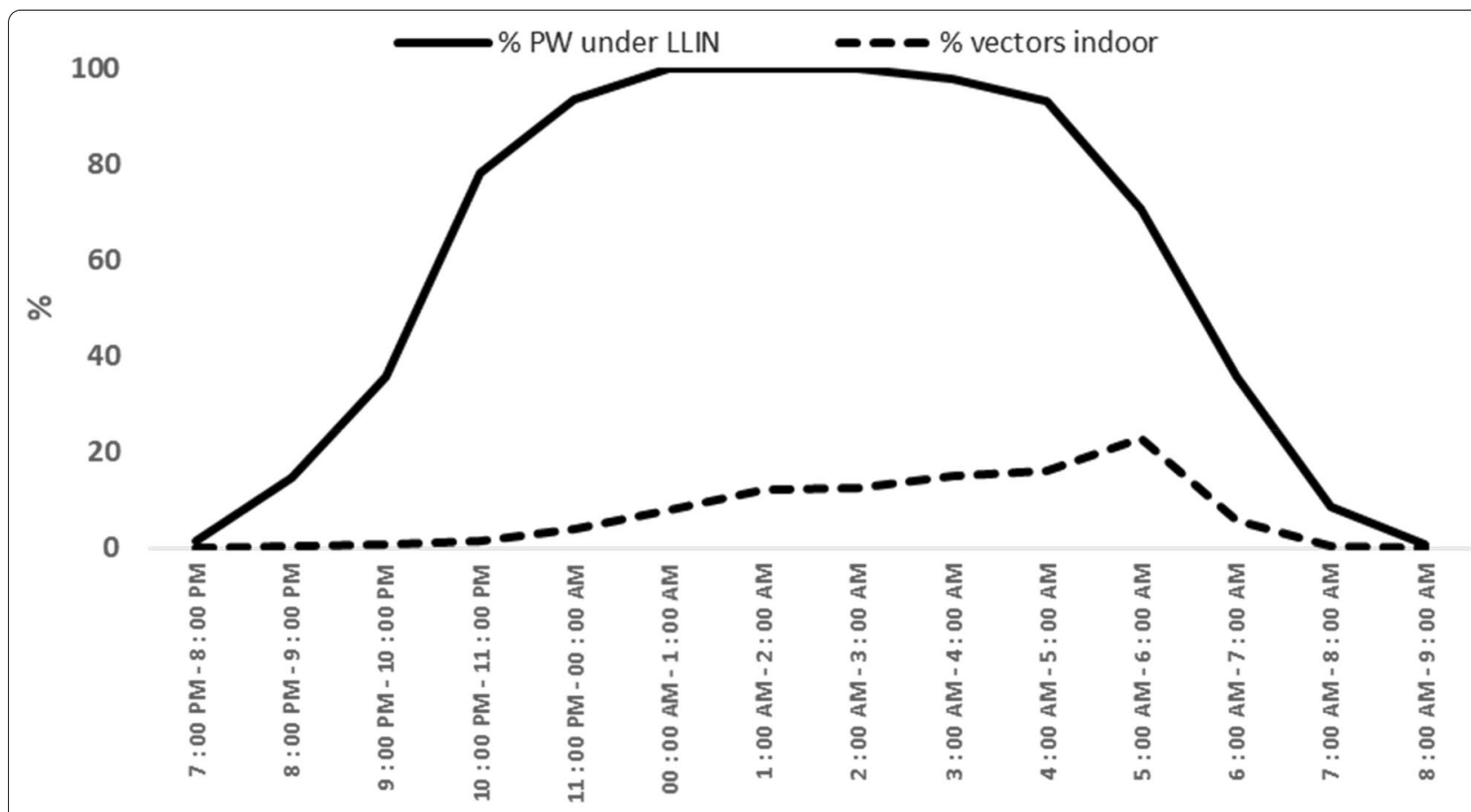

Time periods

Fig. 2 Proportion of pregnant women (PW) under bed nets and proportion of vectors collected indoor per period

\section{Malaria vectors species and Plasmodium falciparum} infection

From the 3848 females of Anopheles gambiae s. l. collected, 1383 were randomly selected and successfully identified at species level using PCR. Almost all
Anopheles gambiae s. l. tested were Anopheles coluzzi except 2 which were Anopheles melas (Theobald 1903) (Diptera: Culicidae).

The overall CSP index was $1.85 \pm 0.01 \%$ (Table 1 ). CSP antigen index showed a spatial heterogeneity ranging

Table 1 CSP antigen index in malaria vectors and Plasmodium falciparum transmission both indoor and outdoor per period with 95\% $\mathrm{Cl}$

\begin{tabular}{|c|c|c|c|c|c|}
\hline & $\mathrm{N}$ vector tested & $\mathrm{N}$ vectors $\mathrm{CSP}^{+}$ & $\mathrm{CSP}^{+}$rate $(\%)$ & $95 \% \mathrm{Cl}$ & (\%) Transmission \\
\hline \multicolumn{6}{|c|}{7 p.m-10 pm } \\
\hline Indoor & 34 & 1 & 2.94 & 0.97 & 1.41 \\
\hline Outdoor & 17 & 0 & 0.00 & 0.00 & 0.00 \\
\hline Total & 51 & 1 & 1.96 & 0.53 & 1.41 \\
\hline \multicolumn{6}{|c|}{10 pm-6am } \\
\hline Indoor & 1998 & 39 & 1.95 & 0.01 & 54.93 \\
\hline Outdoor & 1492 & 28 & 1.88 & 0.02 & 39.44 \\
\hline Total & 3490 & 67 & 1.92 & 0.01 & 94.37 \\
\hline \multicolumn{6}{|l|}{6 am-9 am } \\
\hline Indoor & 139 & 1 & 0.72 & 0.12 & 1.41 \\
\hline Outdoor & 168 & 2 & 1.19 & 0.13 & 2.82 \\
\hline Total & 307 & 3 & 0.98 & 0.06 & 4.23 \\
\hline \multicolumn{6}{|l|}{ Total } \\
\hline Indoor & 2171 & 41 & 1.89 & 0.01 & 57.75 \\
\hline Outdoor & 1677 & 30 & 1.79 & 0.02 & 42.25 \\
\hline Total & 3848 & 71 & 1.85 & 0.01 & 100 \\
\hline
\end{tabular}


from 0\% (in Awomey-Gbèkpa, Awomey-Gblon and Nonhouéto villages) to $5.77 \pm 0.88 \%$ in Hounhouè village. Respectively $1.41 \%, 94.37 \%$ and $4.23 \%$ of Plasmodium falciparum transmission occurred during the periods 7 p.m-10 p.m.; 10 p.m-6 a.m. and 6 a.m-9 a.m. (Table 1).

The endophagy, was estimated on the total sample at $56.4 \pm 0.01 \%$. Endophagy was significantly higher $(\mathrm{df}=1, \mathrm{p}=0.005)$ at the early evening $(7 \mathrm{p} . \mathrm{m}-10 \mathrm{p} . \mathrm{m}$. $66.7 \pm 12.9 \%)$ compared to the early morning (6 a.m -9 a.m., 45.2 $\pm 5.6 \%$ ), (Additional file 2: Table S2).

\section{Allelic frequency of kdr gene in Anopheles gambiae s.l.}

The allelic frequency of $k d r$ gene in Anopheles gambiaes. $l$. collected in the villages was $74.4 \%$. No significant difference $(\mathrm{df}=1, \mathrm{p}=0.186)$ was observed between the allelic frequency of this gene indoors $(75.4 \%)$ and outdoors (73.3\%) on the total sample (Additional file 3: Table S3). However, the allelic frequency of $k d r$ gene in Anopheles gambiae s. $l$. biting human indoors early morning (6 a.m-9 a.m.), 82.0 [77.5-86.5] \% seems higher than that of Anopheles gambiae s. l. biting human outdoors during the same period (72.8 [68.0-77.5] \%), but difference was not significant $(\mathrm{df}=1, \mathrm{p}=0.816)$.

\section{Discussion}

The present study reported precious data, seen that such data on aggressiveness rhythm and human behaviour collected simultaneously in the same setting are rare. Data shows that despite a slight early evening and early morning biting activity of malaria vectors, more than $90 \%$ of malaria vectors bites and Plasmodium falciparum transmission occurred between 10 p.m. and 6 a.m., a period at which over $80 \%$ of pregnant women were under bed net in the study area. The main malaria vector in the study area was Anopheles coluzzi with a CSP index and an allelic frequency of $k d r$ gene equal respectively to $1.9 \%$ and $74.4 \%$.

The early evening and early morning biting activity reported in this study are consistent with recent findings on Anopheles funestus in Southern Benin [5]. Despite this unusual malaria vectors biting activity in the study area, bed net remains a useful protection tool against mosquito biting since more than $90 \%$ of bites and Plasmodium falciparum transmission occurred between $10 \mathrm{p}$.m. and 6 a.m., period during which most pregnant women were in bed under bed net. Analysing data collected in 2011 on behavioral interactions between Anopheles funestus and humans in two villages of southern Benin, Moiroux et al. showed that the true average personal protection of LLITNs remained very high (> 80\%), despite the change in this vector biting peak [19]. The critical challenge for malaria control in the study area seems to remain the good use, bio efficacy and the physical integrity of LLITNs. Indeed, as reported by Hounkonnou et al., around $90 \%$ of pregnant women in the study area used bed net, but less than $10 \%$ of bed net used by pregnant women attained WHO bio-efficacy criteria [8]. It is also important to note that in the present study, aggressiveness and transmission had a very high spatial heterogeneity ranging from 2.33 bites ( 0 infected bite) per person per night in Awomey-Gbèkpa village to 185.66 bites (4 infected bites) per person per night in Todo village. These findings highlight the existence of local foci of transmission in the study area where the aggressiveness and transmission remain high even in the timeframe 6 a.m. -9 a.m. when majority of pregnant women were not under LLITNs. In Todo village, aggressiveness and transmission were respectively 14.85 bites per person and 0.32 infected bites per person during this timeframe).

The study area is a natural lake influenced by the Atlantic Ocean and previous studies carried out 2 decades ago in neighbouring lagoon areas reported that Anopheles melas represents $80 \%$ of Anopheles gambiae s.l. [20, 21]. The low Anopheles melas proportion reported in the present study was recently reported in the same district [9], and could be due to its urbanized nature which has probably led to the proliferation of breeding sites of Anopheles coluzzii at the detriment of Anopheles melas [9, 20]. Since Anopheles melas is known to have a sporozoitic index significantly lower than that of Anopheles coluzzii [20-22], the relative proliferation of breeding sites of Anopheles coluzzii is a potential health concern considering malaria transmission in this area. However, subsequent increase in malaria transmission in this area have been masked by the large scale implementation of vectors control tools (e.g. Long Lasting Insecticidal Nets) [9]. A recent study carried out in this study area showed a general high possession of bed nets by the pregnant women with more than 8 out of 10 women using it [8].

The allelic frequency of $k d r$ gene in Anopheles coluzzii reported in the present study is consistent with that reported recently in neighbouring villages [9] and was lower than $100 \%$ observed in Cotonou, a neighbouring district. As fishing is the most important economic activity in the study area, there is a lower use of insecticides linked to agriculture. The insecticide resistance selection in this area could be due to the domestic use of insecticide for vectors control [9]. In addition, an increase in the activity of vegetable farming in neighbouring districts [23] has led to the use of insecticides in an improper manner to control vegetable pests and pesticide residues from these areas can also contribute to insecticide resistance selection in the study area [9]. 


\section{Conclusion}

The present study revealed a non-negligible early evening and early morning biting activity of malaria vectors in the study area. However, the major part of transmission occurs at a period when more than $80 \%$ of pregnant women were on bed under bed net. Findings of this study indicate that in the study area, there is no argument indicating that the good use of LLITNs do not provide to pregnant protection against mosquito biting and malaria transmission. Then the use of LLITNs with good physical integrity and bio-efficacy have to be promoted among pregnant women despite changes in vectors aggressiveness rhythm.

\section{Limitations}

This study design is an observational cross-sectional and mosquito collection was carried out in 3 different points only for one night due to logistic reasons. This could be considered as a limitation, and a longitudinal design may have brought a higher level of evidence. However, the data collected is precious because such data; aggressiveness rhythm and human behaviour collected simultaneously in the same setting, are rare. Essentially, it is of crucial importance to monitor these indicators at a high scale and with a higher frequency.

\section{Abbreviations}

CSP: Circumsporozoite protein; ELISA: Enzyme-linked immunosorbent assays; HLCs: Human landing catches; IRS: Indoor residual spraying; Kdr: Knockdown resistance; LLITNs: Long lasting insecticidal treated nets; PCR: Polymerase chain reaction; s. I.: Sensu lato; WHO: World Health Organisation.

\section{Supplementary Information}

The online version contains supplementary material available at https://doi. org/10.1186/s13104-021-05615-7.

Additional file 1: Table S1. Number of malaria vectors caught and CSP antigen index per village with $95 \% \mathrm{Cl}$.

Additional file 2: Table S2. Endophagy according to the periods with $95 \% \mathrm{Cl}$.

Additional file 3: Table S3. Resistance gene $k d r_{w}$ in malaria vectors according to the periods.

\section{Acknowledgements}

We thank the populations and local authorities of Sô-Ava District for their collaboration during the present study. We also thank volunteers involved in mosquito collection.

\section{Authors' contributions}

$A D$ and $G C$ conceived of the study. $A D$ and $A B, C S$ have participated in the data collection on field. AB and CS carried out laboratory assays. AD and GC have participated in the analysis and interpretation of data. SE has realized the map of the study area. The manuscript was drafted by AD. SE revised the language. All authors read and approved the final manuscript.

\section{Funding}

"Expertise France-Initiative 5\%", (Mission N 15SANIN110) funded data collection during this study.

\section{Availability of data and materials}

The datasets during and/or analysed during the current study are available from the corresponding author on reasonable request.

\section{Declarations}

Ethics approval and consent to participate

Ethical clearance $N^{\circ} 09$ (May, 28th 2015) was given for the study by the National Ethical Committee in Benin (Comité National d'Ethique pour la Recherche en Santé). Collectors (people that were used for collecting mosquitoes from their bodies) gave prior written informed consent and were vaccinated against yellow fever and medically supervised by local physicians in case of illness.

\section{Consent for publication}

Not applicable.

\section{Competing interests}

The authors declare that they have no competing interests.

\section{Author details}

${ }^{1}$ Centre de Recherche Entomologique de Cotonou (CREC), 06 BP 2604 Cotonou, Bénin. ${ }^{2}$ Centre de Recherche pour la lutte contre les Maladies Infectieuses Tropicales (CReMIT), Université d'Abomey-Calavi (UAC), BP 526 Cotonou, Bénin. ${ }^{3}$ Heartland Alliance, Lagos, Nigeria. ${ }^{4}$ UMR216-MERIT, Institut de Recherche pour le Développement, 75006 Paris, France.

Received: 25 March 2021 Accepted: 13 May 2021

Published online: 22 May 2021

\section{References}

1. WHO World Malaria Report 2015. WHO. http://www.who.int/malaria/ publications/world-malaria-report-2015/report/en/. Accessed 4 Dec 2020.

2. World malaria report 2019. https://www.who.int/publications-detail-redir ect/9789241565721. Accessed 4 Dec 2020

3. N'Guessan R, Corbel V, Akogbéto M, Rowland M. Reduced efficacy of insecticide-treated nets and indoor residual spraying for malaria control in pyrethroid resistance area Benin. Emerg Infect Dis. 2007;13:199-206.

4. Ranson $\mathrm{H}$, Lissenden $\mathrm{N}$. Insecticide resistance in african anopheles mosquitoes: a worsening situation that needs urgent action to maintain malaria control. Trends Parasitol. 2016;32:187-96.

5. Moiroux N, Gomez MB, Pennetier C, Elanga E, Djènontin A, Chandre F, et al. Changes in Anopheles funestus biting behavior following universal coverage of long-lasting insecticidal nets in Benin. J Infect Dis. 2012;206:1622-9.

6. Durnez L, Mao S, Denis L, Roelants P, Sochantha T, Coosemans M. Outdoor malaria transmission in forested villages of Cambodia. Malar J. 2013;12:329.

7. Wamae PM, Githeko AK, Otieno GO, Kabiru EW, Duombia SO. Early biting of the Anopheles gambiae s.s. and its challenges to vector control using insecticide treated nets in western Kenya highlands. Acta Trop. 2015;150:136-42.

8. Hounkonnou C, Djènontin A, Egbinola S, Houngbegnon P, Bouraima A, Soares $C$, et al. Impact of the use and efficacy of long lasting insecticidal net on malaria infection during the first trimester of pregnancy -a pre-conceptional cohort study in southern Benin. BMC Public Health. 2018;18:683.

9. Djènontin A, Zogo B, Ahlonsou J, Bouraima A, Ibikounle $M$, Courtin D, et al. Mosquitoes fauna diversity, Plasmodium falciparum infection and insecticide resistance status in malaria vectors in a lagoon area in Southern Benin, West Africa. Int J Multidiscip Curr Res. 2017. https://doi.org/10. 14741/ijmcr/v.5.1.23.

10. Djènontin A, Bio-Bangana S, Moiroux N, Henry M-C, Bousari $O$, Chabi J, et al. Culicidae diversity, malaria transmission and insecticide resistance alleles in malaria vectors in Ouidah-Kpomasse-Tori district from Benin (West Africa): a pre-intervention study. Parasit Vectors. 2010;3:83. 
11. Gillies MT. A supplement to the Anophelinae of Africa south of the Sahara (Afrotropical Region). Publ S Afr Inst Med Res. 1987;55:1-143.

12. Funestus (A) Les Anophèles de la région afro-tropicale. Editions IRD. 1998. http://bioinfo-web.mpl.ird.fr/identiciels/anopheles/html/taxa/funestus_ A .html. Accessed 25 Mar 2021.

13. Wirtz RA, Burkot TR, Graves PM, Andre RG. Field evaluation of enzymelinked immunosorbent assays for Plasmodium falciparum and Plasmodium vivax sporozoites in mosquitoes (Diptera: Culicidae) from Papua New Guinea. J Med Entomol. 1987:24:433-7.

14. Livak KJ. Organization and mapping of a sequence on the Drosophila melanogaster $X$ and $Y$ chromosomes that is transcribed during spermatogenesis. Genetics. 1984;107:611-34.

15. Scott JA, Brogdon WG, Collins FH. Identification of single specimens of the Anopheles gambiae complex by the polymerase chain reaction. Am J Trop Med Hyg. 1993;49:520-9.

16. Favia G, Lanfrancotti A, Spanos L, Sidén-Kiamos I, Louis C. Molecular characterization of ribosomal DNA polymorphisms discriminating among chromosomal forms of Anopheles gambiae s.s. Insect Mol Biol. 2001;10:19-23.

17. Santolamazza F, Mancini E, Simard F, Qi Y, Tu Z, della Torre A. . Insertion polymorphisms of SINE200 retrotransposons within speciation islands of Anopheles gambiae molecular forms. Malar J. 2008;7:163. https://doi.org/ 10.1186/1475-2875-7-163.

18. Bass C, Nikou D, Donnelly MJ, Williamson MS, Ranson H, Ball A, et al. Detection of knockdown resistance $(\mathrm{kdr})$ mutations in Anopheles gambiae: a comparison of two new high-throughput assays with existing methods. Malar J. 2007;6:111. https://doi.org/10.1186/1475-2875-6-111.

19. Moiroux N, Damien GB, Egrot M, Djenontin A, Chandre F, Corbel V, et al. Human exposure to early morning Anopheles funestus Biting behavior and personal protection provided by long-lasting insecticidal nets. PLoS One. 2014;9:e104967. https://doi.org/10.1371/journal.pone.0104967.

20. Akogbéto M. Lagoonal and coastal malaria at Cotonou: entomological findings. Sante. 2000;10:267-75.

21. Akogbeto M, Romano R. Infectivity of Anopheles melas vis-a-vis Plasmodium falciparum in the coastal lagoon area of Benin. Bull Soc Pathol Exot. 1990;1999(92):57-61.

22. Diop A, Molez JF, Konaté L, Fontenille D, Gaye O, Diouf M, et al. Role of Anopheles melas Theobald (1903) on malaria transmission in a mangrove swamp in Saloum (Senegal). Parasite. 2002;9:239-46.

23. Yadouleton AWM, Asidi A, Djouaka RF, Braïma J, Agossou CD, Akogbeto MC. Development of vegetable farming: a cause of the emergence of insecticide resistance in populations of Anopheles gambiae in urban areas of Benin. Malar J. 2009;8:103.

\section{Publisher's Note}

Springer Nature remains neutral with regard to jurisdictional claims in published maps and institutional affiliations.
Ready to submit your research? Choose BMC and benefit from:

- fast, convenient online submission

- thorough peer review by experienced researchers in your field

- rapid publication on acceptance

- support for research data, including large and complex data types

- gold Open Access which fosters wider collaboration and increased citations

- maximum visibility for your research: over $100 \mathrm{M}$ website views per year

At BMC, research is always in progress.

Learn more biomedcentral.com/submissions 